\title{
Assessment of Ecological Sustainability of Resource-based City-A Case Study of Hancheng City, China
}

\author{
Yan Zhu',2a, Lihui Zhou ${ }^{1,2 b}$, Xuan Zhang ${ }^{1,2 c}$, Jun Zhang ${ }^{3 d}$, Hongxia Du ${ }^{3 e^{*}}$, \\ Lanzhou Xü ${ }^{3 f}$, Pengkang Jin ${ }^{3 g}$, Bizhou Ge ${ }^{3 h}$
}

${ }^{1}$ Research Institute of Oil and Gas Technology of Changqing Oilfield Company, Xi'an 710018, People's Republic of China;

${ }^{2}$ National Engineering Laboratory for Exploration and Development of Low-permeability Oil and Gas Field, Xi'an 710018, People's Republic of China;
${ }^{3}$ Shaanxi Key Laboratory of Environmental Engineering, Xi'an University of Architecture and Technology, Xi'an 710055, People's Republic of China.

azhyan8_cq@petrochina.com.cn, bzlh_cq@petrochina.com.cn, 'cxuan_cq@petrochina.com.cn, dnedzhang@163.com, eduhongxia1016@163.com, ${ }^{\text {}}$ Xulanzhouedu@163.com, ${ }^{9}$ pkjin999@qq.com, hgebz@163.com,

Keyword: Ecological footprint; resource-based city; ecological sustainability index; ecological carrying capacity

\begin{abstract}
To assessment the sustainability of resource-based city development from the perspective of ecology, this paper evaluates the sustainable development level and ecological security of HanCheng City with combined method of ecological footprint and the sustainable development index. The results show that the ecological deficit of the resource-based city is $2.7877 \mathrm{hm}^{2} / \mathrm{per}$ capita, resulting in low levels of the sustainable development and ecological safety. The main reason for the problem lies in the high dependence on fossil energy industry, which makes the demand for energy land much larger than the supply. Therefore, it is necessary to enhance the ecological carrying capacity from the aspects of improving the efficiency of resource utilization, adjusting the industrial structure and transforming the mode of economic growth.
\end{abstract}

\section{Introduction}

As an important strategic guarantee base for energy resources in China, resource-based city is an important support for the sustained development of the national economy. However, the unbalance of the ecological environment and the exhaustion of resources under the single industrial structure of the resource-based cities with energy development are also more prominent as the leading industries while bringing economic benefits and technological development ${ }^{[1-2]}$. Therefore, it is particularly necessary to quantitatively measure the sustainability of resource-based cities from an ecological perspective ${ }^{[3]}$. Ecological Footprint $(E F)$ is an effective tool to determine the consumption demand of human activities and to determine whether natural assets are overused ${ }^{[4]}$. It studies the relationship between human activity and natural system from the point of view of biophysical parameters, which are represented by the universal indexes of the productive area for human demand and consumption for natural resources ${ }^{[6]}$.

The economic development of HanCheng City depends mainly on the resource consuming industries, such as coal, electricity, metallurgy, coke and building materials in its economic and technological development zone. It is still based on the mining of resources and primary processing and the large proportion of energy industry alone. The contradiction among development, resources and environment is becoming increasingly prominent. Therefore, it is particularly important to 
correctly handle the sustainable development of economic growth and environmental protection of ecological resources. In this paper, the ecological footprint method and the sustainable development index are used to evaluate the sustainable development level and ecological security of the HanCheng city to provide the basis for the management decision.

\section{Ecological footprint model and calculation method}

The ecological footprint analysis method calculates altogether the size of ecological footprint from the demand side and the size of ecological carrying capacity from the supply side. It evaluates the sustainable development of the research objects by comparing the two indexes.

1) the calculation of ecological footprint (ecological demand). Ecological footprint refers to the bioproductive area that required to meet the natural resources and waste disposal under a certain economy and population scale. The calculation formula is as follows:

$$
E F=N e_{f}=N \sum r_{j} \cdot A_{i} \quad(j=1,2,3, \ldots, 6 ; i=1,2,3, \ldots, 6)
$$

In the formula, $E F$ is the overall ecological footprint of the region; $e_{f}$ is the per capita ecological footprint; $N$ is the population number, and $r_{j}$ is the equilibrium factor of the $j$ class biological productive land; $j$ is the six kinds of ecological land types; $A_{i}$ is the per capita ecological footprint component of the $\mathrm{i}$ consumption project, $\mathrm{hm}^{2} /$ per capita; $i$ is the category of consumer project.

According to the ecological footprint model, the consumption of material and energy is converted to the corresponding land area according to a certain conversion ratio. The equilibrium area of biological productive land mainly considers six types: cultivated land, woodland, pasture, fossil fuel land, building land and water area. According to the international standard, the equilibrium factors of the above six kinds of land classes are 2.8, 1.1, 0.5, 1.1, 2.8 and 0.2 respectively.

2) the calculation of ecological carrying capacity (ecological supply). the ecological carrying capacity refers to the sum of the productive land area provided by the region to mankind. For prudential consideration, $12 \%$ of the biodiversity protection area should be deducted in the calculation of ecological carrying capacity. The calculation formula is as follows:

$$
E C=0.88 N \sum e_{c}=0.88 N \sum A_{j} r_{j} y_{j} \quad(j=1,2,3, \ldots, 6)
$$

In the formula, $E C$ is the total ecological carrying capacity, $\mathrm{hm}^{2} ; e_{c}$ is the per capita ecological carrying capacity; $A_{j}$ is the actual production land area of the actual per capita, $\mathrm{hm}^{2} /$ per capita; $y_{i}$ is the yield factor; $r_{j}$ and $N$ are the same as before. If the ecological footprint of a region exceeds the ecological carrying capacity that the region can provide, that is, $E F>E C$, there will be an ecological deficit; on the other hand, $E F<E C$ is an ecological surplus. The ecological surplus indicates that the ecological capacity of the region is sufficient to support its human load, and the regional development model is relatively sustainable ${ }^{[7-8]}$.

\section{Calculation and analysis of ecological footprint of an energy type city}

\section{Data sources and calculation}

In 2014, Hancheng City's gross domestic product (GDP) was about 30.03 billion yuan based on the 4.026 million of permanent residents in Hancheng City, which are obtained from the Hancheng City Statistical Yearbook (in 2014). After the determination of biological resources and energy consumption, biological resources and energy consumption are converted into bioproductive land area required for providing following consumption according to the calculation formula of ecological footprint. The results are shown in Table 1 and Table 2. 
Table1 ecological footprint of biological resources consumption in Hancheng City in 2014

\begin{tabular}{|c|c|c|c|c|}
\hline Biological resources & $\begin{array}{c}\text { Average output } \\
\left(\mathrm{kg} \cdot \mathrm{hm}^{-2}\right) \\
\end{array}$ & $\begin{array}{l}\text { Yield } \\
(\mathrm{t})\end{array}$ & $\begin{array}{c}\text { Ecological footprints } \\
\left(\mathrm{hm}^{2} / \text { per capita }\right)\end{array}$ & $\begin{array}{c}\text { Bioavailability } \\
\text { land type }\end{array}$ \\
\hline Wheat & 2532 & 37787 & 0.0037 & Arable land \\
\hline Silkworm pea & 852 & 145 & 0.0000 & Arable land \\
\hline Tubers & 12607 & 1920 & 0.0000 & Arable land \\
\hline Corn & 2744 & 30776 & 0.0028 & Arable land \\
\hline Soybean & 1935 & 780 & 0.0001 & Arable land \\
\hline Sorghum & 3200 & 1241 & 0.0001 & Arable land \\
\hline Millet & 2415 & 98 & 0.0000 & Arable land \\
\hline Cotton & 1000 & 120 & 0.0000 & Arable land \\
\hline Oil material & 1856 & 1204 & 0.0002 & Arable land \\
\hline Vegetables & 18000 & 112930 & 0.0016 & Arable land \\
\hline Melon & 21209 & 2786 & 0.0000 & Arable land \\
\hline Other autumn Grain & 2744 & 1284 & 0.0001 & Arable land \\
\hline Pork & 74 & 7628 & 0.0256 & Pasture \\
\hline Beef & 33 & 722 & 0.0054 & Pasture \\
\hline Mutton & 33 & 705 & 0.0053 & Pasture \\
\hline Poultry & 764 & 494 & 0.0002 & Pasture \\
\hline Milk & 502 & 1726 & 0.0009 & Pasture \\
\hline Goats' milk & 502 & 98 & 0.0000 & Pasture \\
\hline Sheep hair & 15 & 59 & 0.0010 & Pasture \\
\hline Mountain wool & 15 & 10 & 0.0002 & Pasture \\
\hline Honey & 50 & 30.5 & 0.0002 & Pasture \\
\hline Fresh eggs & 400 & 2940 & 0.0018 & Pasture \\
\hline Fruits & 9762 & 117112 & 0.0030 & woodland \\
\hline Sichuan Pepper & 385 & 22000 & 0.0142 & woodland \\
\hline Walnut & 2150 & 1000 & 0.0001 & woodland \\
\hline Chinese chestnut & 1311 & 65 & 0.0000 & woodland \\
\hline $\log$ & $1.99^{*}$ & $944000^{* *}$ & 0.1178 & woodland \\
\hline Freshwater products & 29 & 720 & 0.0062 & waters \\
\hline
\end{tabular}

the unit is $\mathrm{m}^{3} / \mathrm{hm}^{2} ;{ }^{* *}$ the unit is $\mathrm{m}^{3}$

Table2 Ecological footprint of industry and energy consumption in Hancheng City in 2014

\begin{tabular}{cccccc}
\hline $\begin{array}{c}\text { Consumer } \\
\text { projects }\end{array}$ & $\begin{array}{c}\text { Consumption } \\
(\mathrm{t})\end{array}$ & $\begin{array}{c}\text { Conversion } \\
\text { coefficient } \\
\left(\mathrm{GJ} \cdot \mathrm{t}^{-1}\right)\end{array}$ & $\begin{array}{c}\text { Energy } \\
\text { footprint } \\
\left(\mathrm{GJ} \cdot \mathrm{hm}^{-2}\right)\end{array}$ & $\begin{array}{c}\text { Ecological } \\
\text { footprint } \\
\left(\mathrm{hm}^{2} / \text { per capita }\right)\end{array}$ & $\begin{array}{c}\text { Bioavailability } \\
\text { land type }\end{array}$ \\
\hline Coal & 27683238 & 20.934 & 55 & 2.61714 & Fossil energy land \\
Coke & 2213626 & 28.47 & 55 & 0.28461 & Fossil energy land \\
Crude oil & 24 & 41.868 & 93 & 0.00000 & Fossil energy land \\
Gasoline & 272 & 43.124 & 93 & 0.00003 & Fossil energy land \\
Diesel oil & 6103 & 42.705 & 93 & 0.00070 & Fossil energy land \\
Blast furnace gas & 533 & 53.38 & 71 & 0.00010 & Steel Energy land \\
Coke oven gas & 116 & 177.9 & 71 & 0.00007 & Steel Energy land \\
Natural gas & 2.4 & 355.88 & 71 & 0.00000 & Fossil energy land \\
Power & $3579750^{*}$ & $3.36^{* *}$ & 1000 & 0.00299 & Construction land \\
\hline
\end{tabular}

*the unit is $\mathrm{GWh}$; ** the unit is $\mathrm{GJ} \cdot \mathrm{GWh}^{-1}$ 


\section{Results and analysis}

According to the ecological footprint calculation model with Table 1 and Table 2, it is calculated that the ecological footprint $(E F)$ of Hancheng in 2014 is $3.3187 \mathrm{hm}^{2} /$ per capita; the ecological carrying capacity of $E C$ is $0.5310 \mathrm{hm}^{2} /$ per capita, and there is an ecological deficit (EC)of 2.7877 $\mathrm{hm}^{2} /$ per capita. The ecological footprint is about six times that of the available ecological carrying capacity. It shows that the consumption of ecological resources is far beyond the scope of its ecological carrying capacity. High energy consumption, reduced arable land and huge consumption of fossil fuel are the main reasons for the high ecological deficit.

In this study, the ecological sustainability index $(E S I)$ is introduced to further evaluate the utilization of its resources. ESI indicates the degree of ecological sustainable utilization in a region, which refers to the degree of ecological sustainable supply of a certain area to meet the needs of human ecology ${ }^{[10]}$. The formula is as follows: $E S I=E C /(E C+E F)$. The ecological sustainability index is between $0 \sim 1$, when $E S I$ is $0.5, E C$ and $E F$ are equal, indicating that the two are in equilibrium. According to the results of ecological footprint and ecological carrying capacity in Table 1 and Table 2, the ecological sustainability index ESI is 0.138. Thus, the ecological economic development of Hancheng City has shown strong unsustainability, which makes its ecological footprint of energy consumption far exceeds its ecological carrying capacity. Its ecological demand is far beyond the supply of natural resources, and the over dependence on the excessive consumption of raw coal in this area is a single development side. This will inevitably lead to the reduction of ecological security in the area.

Based on the analysis of the ecological carrying capacity and sustainable development of Hancheng City, the following aspects should be improved: (1) Mining coal and other mineral resources in a rational and effective way. The non-renewable nature of mineral resources makes the development of resource-based cities unable to rely on mineral resources for a long time and is bound to face the challenge of exhaustion of resources; (2) Readjust the industrial structure, speed up industrial transformation and transform the mode of economic growth. So mineral resources are gradually reduced by the economic development, and changing the energy consumption structure, improving production efficiency, changing the extensive economic development mode to enhance ecological carrying capacity and improve ecological safety; (3) To improve the ecological responsibility consciousness of the enterprises and residents. A resource-based city based on heavy industry seeks economic benefits and ignores the coordination relationship between economic development and environment, which makes the ecological environment be destroyed to great extent. To alleviate the increasingly serious shortage of energy resources and the pressure of environmental pollution, the efforts of the whole society are needed. Especially, the units and residents in the social and economic activities are needed to strengthen the consciousness of energy saving and consumption reduction of the whole society, which play an important role in the sustainable development of the city's economy and society.

\section{Conclusion}

Hancheng City, as a resource-based city, has an ecological footprint of $3.3187 \mathrm{hm}^{2} /$ per capita and ecological carrying capacity of $0.5310 \mathrm{hm}^{2} /$ per capita. However, there are ecological deficit of $2.7877 \mathrm{hm}^{2} /$ per capita and ecological sustainability index of 0.138 showing an exorbitant carbon footprint a strong unsustainable development degree in urban construction. The core problem is that the urban industry relies heavily on the fossil energy industry, making the ecological footprint of its energy consumption far exceed its ecological carrying capacity. Therefore, in the future, it is necessary to improve the efficiency of resource, to adjust the industrial structure and to change the mode of economic growth for strength of the ecological carrying capacity and acceleration of the 
formation of energy saving society. Efforts should be made to support the city's economic development with reasonable consumption of resources.

\section{Acknowledgements}

This work was financially supported by the Major Science and Technology Projects of PetroChina Co. Ltd (2014E-3605), the National Natural Science Foundation of China (Grants: 40706032), the Shaanxi Natural Science Foundation (2014JM7260) and the Education Department Scientific Research Fund of Shaanxi Province (Grants: 17JK0428).

\section{Reference}

[1] Liu Benle, Chen Xiaoyang, Chen Min, Wang Fang, Zhou Yuzhi. Study on the dynamic changes of carbon footprint and carbon bearing capacity of coal resource-based cities [J]. Coal Engineering, 2017, 49 (2): 124-127.

[2] Guo Cunzhi, Huang Qing, He Ying Fei. Decomposition and difference analysis of energy consumption growth in resource-based cities [J]. China Population, Resources and Environment, 2017, 27 (1): 73-82.

[3] Zhu Lin, Bian Zheng Fu, Zhao Hua, Yu Jian. Analysis of the ecological footprint of the transformation of resource exhausted cities -- Taking Jiawang District of Xuzhou as an example, [J]. China Land Science, 2013, 27 (5): 78-84.

[4] Zhou Tao, Wang Yunpeng, Gong Jianzhou, Wang Fang, Feng Yanfen. Model revision and method improvement of ecological footprint [J]. Ecological Journal, 2015, 35 (14): 4592-4603.

[5] Jin Xiangmu, Liu Qian Kun. Study on the land carrying capacity index based on the expansion of three-dimensional ecological footprint model -- Taking Wenzhou as an example [J]. Ecological Journal, 2017, 37 (9): 2982-2993.

[6] Li Bingyi, Shi Xueyi. Analysis of sustainable development ability of resource-based cities based on Ecological Footprint-Taking Jincheng Shanxi Province as an example[J]. Soil and Water Conservation, 2016, 23 (2): 255-261.

[7] Galli A, Kitzes J, Niccolucci V, Wackernagel M, Wada Y, Marchettini N. Assessing the Global Environmental Consequences of Economic Growth through the Ecological Footprint: A Focus on China and India [J]. Ecological Indicators, 2012, 17: 99-107.

[8] Borucke M, Moore D, Cranston G, Gracey K, Iha K. The effects of globalization on Ecological Footprints: an empirical analysis[J]. Environment, Development and Sustainability, 2017, 19: 863-876.

[9] Fang Lei, Yang Zhengdong, Wang Gang, Zhu Jiulong. Research on the sustainable development of coal-based cities based on the ecological footprint method -- Taking Yima city of Henan as an example of [J]. Safety and Environment, 2015, 15 (5): 358-361.

[10] Chen Chen, Xia Xianli. Evaluation of sustainable development of resource-based cities in Western China based on ecological footprint model [J]. Soil and Water Conservation Research, 2012, 19 (1): 197-201. 